\title{
Long Term Assessment of Aerosol Radiative Forcing over Selected Sites of East Africa
}

\author{
John W. Makokha1 ${ }^{*}$, Jared O. Odhiambo1, Juma Godfrey Shem² \\ ${ }^{1}$ Department of Science Technology and Engineering, Kibabii University, Bungoma, Kenya \\ ${ }^{2}$ Department of Mathematics, Kibabii University, Bungoma, Kenya \\ Email: *godfrey.juma@kibu.ac.ke
}

How to cite this paper: Makokha, J.W., Odhiambo, J.O. and Shem, J.G. (2018) Long Term Assessment of Aerosol Radiative Forcing over Selected Sites of East Africa. Journal of Geoscience and Environment Protection, 6, 22-34.

https://doi.org/10.4236/gep.2018.64002

Received: January 26, 2018

Accepted: March 30, 2018

Published: April 2, 2018

Copyright $\odot 2018$ by authors and Scientific Research Publishing Inc. This work is licensed under the Creative Commons Attribution International License (CC BY 4.0).

http://creativecommons.org/licenses/by/4.0/

(c) (i) Open Access

\begin{abstract}
Atmospheric aerosols have contributed to radiative forcing through direct and indirect mechanisms. Aerosol effects are important in computing radiative forcing estimates for the past, current and future climate. In this study, a comprehensive assessment of regional aerosol radiative forcing, Optical Properties of Aerosol and Clouds (OPAC) model (wavelength range of 0.25 $4.0 \mu \mathrm{m}$ ) over selected sites in East Africa was done. Aerosol optical properties constituted the inputs of a Radiative Transfer Model (RTM). Optical properties investigated included Aerosol Optical Depth (AOD), Single Scattering Albedo (SSA) and Asymmetry Parameter (AP). Aerosol Radiative Forcing (ARF) during the study period at the surface (SFC), top of the atmosphere (TOA) and the atmosphere (ATM) was estimated to be $-18.4 \pm 1.4 \mathrm{~W} \cdot \mathrm{m}^{-2}$, $+1.1 \pm 0.3 \mathrm{~W} \cdot \mathrm{m}^{-2}$ and $+19.5 \pm 2.5 \mathrm{~W} \cdot \mathrm{m}^{-2}$, respectively. This corresponds to an increment in net atmospheric forcing at a heating rate of about $0.55 \pm 0.05$ $\mathrm{K} /$ day $(0.41 \pm 0.03$ to $0.78 \pm 0.03 \mathrm{~K} /$ day $)$ in the lower troposphere. The study points out the significant role played by atmospheric aerosols in climate modification over the area of study. It is recommended that a further assessment be done in view of uncertainties that may impact on the findings and which were not within the scope of this research.
\end{abstract}

\section{Keywords}

East Africa, Radiative Forcing, Climate Change, Aerosol Optical Depth, Atmospheric Heating Rate

\section{Introduction}

Atmospheric aerosols are responsible for a radiative forcing (RF) of the atmosphere through multiple processes namely direct and indirect means (the Intergovernmental Panel on Climate Change) [1]. They directly affect climate by ab- 
sorbing and scattering solar radiation which yields a warming and cooling effect respectively on the immediate atmosphere. Likewise, aerosols indirectly modify the properties of clouds by acting as cloud condensation nuclei (CCN) that aids in the formation of cloud droplets. Climate relevant aerosol properties (size distribution, hygroscopicity, chemical composition, mixing state, optical, and cloud nucleation) and their atmospheric distribution constitute directly to its influence on Earths radiation budget.

The direct aerosol effect on RF is estimated to be $-0.35(-0.85$ to +0.15$)$ $\mathrm{W} \cdot \mathrm{m}^{-2}$ (high confidence) [1]. The rapid adjustment to this direct aerosol $\mathrm{RF}$ leads to further negative forcing, particularly through cloud adjustments, and is attributable primarily to black carbon. As a consequence, the direct effective radiative forcing (ERF) is more negative than the direct RF (low confidence) and given a best estimate of about $-0.45(-0.95$ to +0.05$) \mathrm{W} \cdot \mathrm{m}^{-2}$ [1]. The assessment of aerosol direct RF effect is less negative than reported in Fourth Assessment Report (AR4) because of a re-evaluation of aerosol absorption. A recent estimate of aerosol RF over the Kenyan atmosphere was $-0.48 \mathrm{~W} \cdot \mathrm{m}^{-2}$ [2].

Globally, there is an improved understanding of aerosol-cloud interactions which have led to a reduction in the magnitude of many aerosol-cloud forcing estimates [1]. The total ERF due to direct and indirect aerosol effects (excluding the effect of absorbing aerosol on snow and ice) is estimated to be about -0.9 $(-1.9$ to -0.1$) \mathrm{W} \cdot \mathrm{m}^{-2}$ (medium confidence) [1]. This range was obtained by giving equal weight to satellite-based studies and estimates from climate models. The total ERF due to direct and indirect aerosol effects is consistent with multiple lines of evidence suggesting less negative estimates for aerosol-cloud interactions than those discussed in AR4.

The IPCC Report [1] indicates that anthropogenic gas emissions have driven changes in Well-Mixed Greenhouse Gas (WMGHG) concentrations during the industrial era over the globe. This has consequently affected the WMGHGs atmospheric burden globally and regionally, especially $\mathrm{CO}_{2}$ which resulted into an increase in their RF of 2.83 (2.54 to 3.12) W. $\mathrm{m}^{-2}$ from 2005 to 2011 (globally). Moreover, in the last 15 years, $\mathrm{CO}_{2}$ has been the dominant contributor to the increasing RF from the WMGHGs with an average growth rate of slightly less than $0.3 \mathrm{~W} \cdot \mathrm{m}^{-2}$ per decade [1]. Likewise, after a decade of near stability in $\mathrm{CH}_{4}$ emissions, its recent increase enhanced its RF impacts globally as compared to AR4 by about $2 \%$ to $0.48 \%$ ( 0.43 to 0.53$) \mathrm{W} \cdot \mathrm{m}^{-2}$ [1]. Furthermore, atmospheric $\mathrm{N}_{2} \mathrm{O}$ has increased by $6 \%$ since AR4, causing a RF of about $0.17(0.14$ to 0.20$) \mathrm{W} \cdot \mathrm{m}^{-2}$. On the contrary, as the $\mathrm{N}_{2} \mathrm{O}$ concentrations rise, those of dichlorodifluoromethane $\left(\mathrm{CF}_{2} \mathrm{Cl}_{2}, \mathrm{CFC}-12\right)$, the third largest WMGHG contributor to RF for several decades, are consistently decreasing due to phase-out of emissions of this chemical under the Montreal Protocol. Studies by Juma [3] revealed that reducing radiative forcing over Kenya associated with aerosols. The study was not however comprehensive about direct and indirect effects of aerosols and also the radiative 
characteristics of aerosols.

Details of individual WMGHGs and aerosol impact on RF globally together with their level of confidence are provided for in Figure 1.

Short-lived GHGs such as $\mathrm{O}_{3}$ and stratospheric water vapor also contribute significantly to anthropogenic forcing. It has been pointed out from observations that $\mathrm{O}_{3}$ increased at many undisturbed (background) locations through the 1990s which has consistently increased over Asia (though observations cover a limited area) while remaining constant over Europe during the last decade [1]. The total RF due to changes in $\mathrm{O}_{3}$ is 0.35 ( 0.15 to 0.55$) \mathrm{W} \cdot \mathrm{m}^{-2}$ (high confidence), with $\mathrm{RF}$ due to tropospheric $\mathrm{O}_{3}$ of $0.40(0.20$ to 0.60$) \mathrm{W} \cdot \mathrm{m}^{-2}$ (high confidence) and due to stratospheric $\mathrm{O}_{3}$ of $-0.05(-0.15$ to +0.05$) \mathrm{W} \cdot \mathrm{m}^{-2}$ (high confidence). It is of significance to note that $\mathrm{O}_{3}$ is not emitted directly into the atmosphere; instead it is formed by photochemical reactions [4] [5].

This paper presents a comprehensive long term assessment of aerosol radiative forcing over the selected East African sites namely Nairobi $\left(1^{\circ} \mathrm{S}, 36^{\circ} \mathrm{E}\right)$, Mbita $\left(0^{\circ} \mathrm{S}, 34^{\circ} \mathrm{E}\right)$, Mau Forest Complex $\left(0.0^{\circ} \mathrm{S}-0.6^{\circ} \mathrm{S} ; 35.1^{\circ} \mathrm{E}-35.7^{\circ} \mathrm{E}\right)$, Malindi $\left(2^{\circ} \mathrm{S}, 40^{\circ} \mathrm{E}\right)$, Mount Kilimanjaro $\left(3^{\circ} \mathrm{S}, 37^{\circ} \mathrm{E}\right)$ and Kampala $\left(0^{\circ} \mathrm{N}, 32.1^{\circ} \mathrm{E}\right)$ from 2000 to 2013. Selection of the study sites was based on the dominance of anthropogenic influence and availability of AERONET stations that provide ground truthing of the satellite and Optical Properties of Aerosol and Clouds (OPAC)

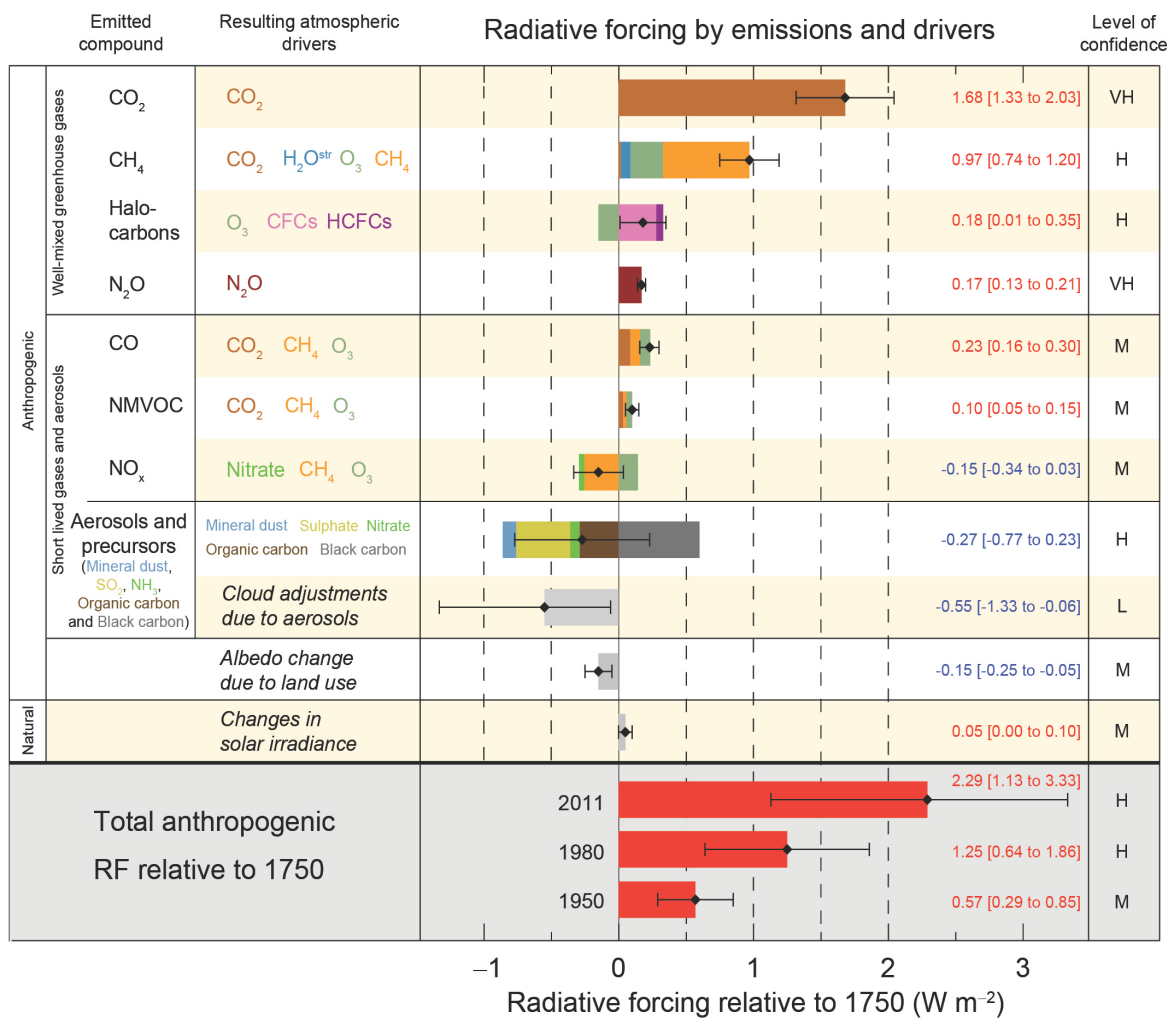

Figure 1. Radiative forcing estimates in 2011 relative to 1750 and aggregated uncertainties for the main drivers of climate change. (Source: [1].) 
model data used in retrieving the regions radiative characteristics. To determine the Aerosol Radiative Forcing (ARF) at surface (SFC), top of the atmosphere (TOA) and atmosphere (ATM), Aerosol Optical Properties (AOP) from the OPAC model were used as inputs to the Coupled Ocean and Atmosphere Radiative Transfer (COART) model based on the Discrete Ordinate Radiative Transfer (DISORT) code [6] [7] [8].

\section{Methodology}

\subsection{Description of Study Area}

The East Africa region covers diverse land forms comprising of glaciated mountains, Semi-Arid, Plateau and Coastal regions. Details and the map illustrating the study region and specifics on each site of study are as shown in [9].

\subsection{Regional Radiative Forcing}

AOP i.e. Aerosol Optical Depth (AOD), Single Scattering Albedo (SSA) and Asymmetry Parameter (AP), derived from Optical Properties of Aerosol and Clouds (OPAC) model (wavelength range of $0.25-4.0 \mu \mathrm{m}$ ) formed the input to a Radiative Transfer Model (RTM). The RTM used in the study was the COART model based on the DISORT code [6] [7] [8]; COART uses a numerical stable algorithm based on DISORT to solve the equations of plane-parallel radiative transfer in vertically inhomogeneous atmosphere.

To calculate the ARF at SFC, TOA and ATM, the COART model requires additional information such as surface albedo (MOD_09, Level 1B) and columnar water vapor content from MODIS-Terra and columnar ozone from OMI. The RTM uses six standard atmospheres vertical profiles namely tropical, mid-latitude summer, mid-latitude winter, sub-arctic summer, sub-arctic winter and US62 [6]. Rainfall data for training set was obtained from TRMM while for predictive studies in precipitation rate; the National Centers for Environmental Prediction (NCEP) reanalysis data was utilized.

The standard tropical profile was used in the current study. The tropical atmospheric profile also requires information about some additional atmospheric components such as column water vapor content and columnar ozone. Due to regional inhomogeneity in aerosol characteristics, each site in the region was assigned to a specific boundary layer aerosol model that minimizes the uncertainty in the derivation of the utilized AOP. Therefore, Nairobi and Kampala utilized the OPAC urban, while Malindi exploited the OPAC maritime tropical and Mbita, Mau forest Complex and Mount Kilimanjaro used the OPAC continental average boundary layer aerosol models.

Estimation of ARF to study aerosol effects on regional atmospheric heating has been implemented by various researchers all over tropical India [10] [11] [12]. To start with, ARF at the TOA/SFC can be defined as the difference in the flux reaching the top of the atmosphere (surface) with and without the presence 
of aerosols in the atmosphere. The clear-sky ARF calculations at TOA and SFC are performed separately with and without aerosols at $15^{\circ}$ solar zenith interval and are used to determine 24-h [13].

$$
\mathrm{ARF}_{\mathrm{TOA}, \mathrm{SFC}}=\frac{\int_{0}^{24}\left[\operatorname{Flux}(\text { net })_{\text {with aerosol TOA,SFC }}-\text { Flux }(\text { net })_{\text {without aerosol TOA,SFC }}\right] \mathrm{d} h}{\int_{0}^{24} \mathrm{~d} h} .
$$

where $\mathrm{d} h$ is the time in hours. The difference between the radiative forcing at the TOA and SFC is defined as the atmospheric forcing and can be written as:

$$
(\Delta F)_{\mathrm{TOA} / \mathrm{SFC}}=\left(F_{N A}\right)_{\mathrm{TOA} / \mathrm{SFC}}-\left(F_{A}\right)_{\mathrm{TOA} / \mathrm{SFC}}
$$

where $\Delta F$ is the radiative forcing, $F_{N A}$ and $F_{A}$ are the fluxes estimated respectively under no aerosol and with aerosol conditions. From these, the ATM forcing due to aerosols $\left(\Delta F_{\mathrm{ATM}}\right)$ is deducted as $\Delta F_{\mathrm{TOA}}-\Delta F_{\mathrm{SFC}}$ with negative and positive ARF values indicating cooling and heating of the Earth-Atmosphere system respectively. As mentioned earlier, fluxes at the TOA and SFC are calculated by the COART model based on the DISORT code (Zhonghai et al., 1994; 2006). Generally, $\Delta F_{\mathrm{ATM}}$ represents the amount of energy trapped by the aerosols present in the atmosphere, which aids in accessing aerosol impacts on global or regional climate. Aerosol impacts on climate are assessed by estimating the atmospheric heating rate via the First Law of Thermodynamics and hydrostatic equilibrium [14].

$$
\frac{\partial T}{\partial t}=\frac{g}{C_{p}} \frac{\Delta F_{\mathrm{ATM}}}{\Delta P}
$$

where $\partial T / \partial t$ is the heating rate in $\mathrm{K} \cdot \mathrm{day}^{-1}, g$ is acceleration due to earth's gravity, $C_{p}$ is specific heat capacity of air at a constant pressure $=1006 \mathrm{~J} \cdot \mathrm{kg}^{-1} \cdot \mathrm{K}^{-1}$, $\Delta F_{\mathrm{ATM}}$ is the atmospheric forcing. $\Delta P$ is the atmospheric pressure difference taken as $300 \mathrm{hPa}$ which is equal to the pressure difference between surface and 3 $\mathrm{km}$ altitude. The concept behind this assumption is that the large amounts of aerosols are concentrated from surface to $\sim 3 \mathrm{~km}$ altitude [15]. In order to estimate change in incoming solar radiation caused by aerosols over the observational sites, calculations were made for extraterrestrial solar radiations using Equation 4.30 (Iqbal 1983):

$$
H_{o}=I_{s c}\left(\frac{r_{o}}{r}\right)^{2} 2\left[\frac{\cos \phi \cos \delta \sin \omega+\omega \sin \phi \sin \delta}{\pi}\right] .
$$

where $H_{o}$ is extraterrestrial solar radiation, $I_{s c}$ is solar constant taken 1367 $\mathrm{W} \cdot \mathrm{m}^{-2},\left(r_{o} / r\right)^{2}$ is eccentricity correction factor, $\phi$ is the geographic latitude of the observation site, $\delta$ is solar declination angle which is the angle between the line joining the centre of the sun and Earth to the equatorial plane, $\omega$ is the hour angle which is measured at the celestial pole between the observer's longitude and solar longitude and taken at noon equal to zero. 


\section{Results and Discussions}

\section{Regional Radiative Forcing}

To enhance the confidence in the results, AOD (at $550 \mathrm{~nm}$ ) and $\AA \mathrm{E}$ (at 470 - 660 $\mathrm{nm}$ ) measured over the six study sites are compared to the derived OPAC values and found to be in good agreement as shown in Table 1. Additionally, seasonal mean atmospheric parameters such as columnar ozone (DU), precipitable water vapor $(\mathrm{cm})$ and accumulated rainfall $(\mathrm{mm})$ were used in process of radiative modeling via the COART model over each study site for the period of study are also presented.

The SSA average at $550 \mathrm{~nm}$ during the study period was found to be $0.811 \pm$ 0.05 and varied between $0.611 \pm 0.04$ and $0.956 \pm 0.06$. Seasonal variability in the SSA was also exhibited during the study period across all the study sites i.e. SON season $(0.875 \pm 0.03-0.899 \pm 0.02)$, followed by MAM $(0.810 \pm 0.04-0.853 \pm$ $0.05), \mathrm{DJF}(0.611 \pm 0.04-0.778 \pm 0.06)$ and JJA $(0.754 \pm 0.07-0.796 \pm 0.03)$. A seasonal change in the absorbing nature of atmospheric aerosols over the region is depicted by the higher SSA values of SON and MAM seasons as compared to that of the DJF and JJA seasons over the region. Likewise, the monthly average values of AP estimated around $0.697 \pm 0.02$ and varied between $0.627 \pm 0.02$ and $0.711 \pm 0.04$ over the entire East African region. Seasonally, AP at $550 \mathrm{~nm}$ depicted different values with season's i.e. SON, MAM, DJF and JJA were $0.678 \pm$ $0.01,0.673 \pm 0.04,0.648 \pm 0.05$ and $0.645 \pm 0.03$, respectively. The higher value of AP in SON season indicates that the size distribution is dominated by coarse-mode aerosols.

Variation of both downward and upward irradiance with the SZA over each study site during the study period was examined (see Figure 2(a), Figure 2(b)). It was established that the two irradiances decrease with increasing SZA over each of the study site. The decrease is more significant at larger SZA since most of the incoming solar radiation is diffuse in nature due to scattering effects. The low sun case $\left(\mathrm{SZA} 0^{\circ}-\mathrm{SZA} 20^{\circ}\right.$ ) is characterized by high down welling irradiances since most of the incoming solar radiation is direct and strikes the surface at a glancing angle unlike in the high sun case (SZA $50^{\circ}-$ SZA $80^{\circ}$ ) where most of the down welling irradiance is diffuse, hence the low spectral irradiance values [8]. Figure 1(b) shows that upward irradiances in the atmosphere over the study sites decrease with increasing SZA that is attributable to strong Fresnel reflection on the Earth's surface [8].

As stated earlier, the OPAC model derived values were utilized as an input to RTM to calculate ARF; as a result, uncertainty in the calculated ARF needs to be quantified especially when the magnitude of the forcing is small. Generally, uncertainties arise from the estimation of composition of aerosol types, state of mixing assumptions and the vertical distribution of aerosols. The uncertainties in SSA and AOD between OPAC and AERONET/MODIS values were estimated at $\sim 6 \%$ and $\sim 7 \%$, respectively while that of AP was quite low $(\sim 0.7 \%)$. Additionally, the combined effect of atmospheric condition and surface albedo was found 
Table 1. Comparisons of seasonal mean AOD and ÅE from observed measurements as compared to the modeled values from OPAC and Seasonal mean atmospheric parameters over each study site during the study period.

\begin{tabular}{|c|c|c|c|c|c|c|}
\hline \multirow{2}{*}{ Site } & \multirow{2}{*}{ Parameters } & \multirow{2}{*}{ Observed/model } & \multicolumn{4}{|c|}{ Season } \\
\hline & & & DJF & MAM & JJA & SON \\
\hline \multirow{9}{*}{$\begin{array}{l}\overrightarrow{\tilde{0}} \\
\overrightarrow{\tilde{z}} \\
\vec{z}\end{array}$} & & AERONET/MODIS & $0.24 \pm 0.07$ & $0.18 \pm 0.05$ & $0.20 \pm 0.04$ & $0.16 \pm 0.06$ \\
\hline & $\mathrm{AOD}(550 \mathrm{~nm})$ & OPAC Derived & $0.26 \pm 0.06$ & $0.20 \pm 0.07$ & $0.23 \pm 0.08$ & $0.18 \pm 0.07$ \\
\hline & & RMSE & 0.02 & 0.03 & 0.02 & 0.02 \\
\hline & & AERONET/MODIS & $1.43 \pm 0.33$ & $1.04 \pm 0.26$ & $1.53 \pm 0.24$ & $1.36 \pm 0.14$ \\
\hline & $\AA ̊ \mathrm{E}(470-660 \mathrm{~nm})$ & OPAC Derived & $1.40 \pm 0.14$ & $1.06 \pm 0.21$ & $1.51 \pm 0.11$ & $1.30 \pm 0.25$ \\
\hline & & RMSE & 0.02 & 0.02 & 0.03 & 0.04 \\
\hline & Columnar ozone (DU) & OMI & $268 \pm 15$ & $283 \pm 13$ & $264 \pm 12$ & $278 \pm 20$ \\
\hline & Precipitable water vapor $(\mathrm{cm})$ & MODIS-Terra & $1.4 \pm 0.4$ & $4.5 \pm 0.3$ & $1.1 \pm 0.5$ & $2.5 \pm 0.9$ \\
\hline & Rainfall (mm) & From NCEP re-analysis & 10.90 & 138.87 & 37.36 & 114.03 \\
\hline \multirow{9}{*}{ 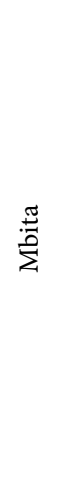 } & & AERONET/MODIS & $0.21 \pm 0.06$ & $0.15 \pm 0.05$ & $0.20 \pm 0.07$ & $0.18 \pm 0.05$ \\
\hline & $\mathrm{AOD}(550 \mathrm{~nm})$ & OPAC Derived & $0.23 \pm 0.05$ & $0.20 \pm 0.06$ & $0.21 \pm 0.04$ & $0.19 \pm 0.03$ \\
\hline & & RMSE & 0.03 & 0.03 & 0.01 & 0.03 \\
\hline & & AERONET/MODIS & $1.46 \pm 0.31$ & $1.14 \pm 0.26$ & $1.57 \pm 0.20$ & $1.46 \pm 0.17$ \\
\hline & $\AA ̊ \mathrm{E}(470-660 \mathrm{~nm})$ & OPAC Derived & $1.43 \pm 0.14$ & $1.10 \pm 0.21$ & $1.56 \pm 0.12$ & $1.43 \pm 0.11$ \\
\hline & & RMSE & 0.01 & 0.03 & 0.01 & 0.02 \\
\hline & Columnar ozone (DU) & OMI & $264 \pm 17$ & $278 \pm 19$ & $260 \pm 18$ & $271 \pm 21$ \\
\hline & Precipitable water vapor $(\mathrm{cm})$ & MODIS-Terra & $1.8 \pm 0.6$ & $4.9 \pm 0.5$ & $1.6 \pm 0.4$ & $3.0 \pm 0.7$ \\
\hline & Rainfall (mm) & From NCEP re-analysis & 12.30 & 137.31 & 34.86 & 114.61 \\
\hline \multirow{8}{*}{$\begin{array}{l}\overrightarrow{\vec{z}} \\
\dot{\Xi} \\
\vec{\Xi}\end{array}$} & & AERONET/MODIS & $0.26 \pm 0.08$ & $0.20 \pm 0.05$ & $0.22 \pm 0.06$ & $0.20 \pm 0.07$ \\
\hline & AOD $(550 \mathrm{~nm})$ & OPAC Derived & $0.28 \pm 0.07$ & $0.22 \pm 0.04$ & $0.25 \pm 0.03$ & $0.21 \pm 0.06$ \\
\hline & & RMSE & 0.02 & 0.02 & 0.01 & 0.02 \\
\hline & & AERONET/MODIS & $1.01 \pm 0.11$ & $0.99 \pm 0.13$ & $0.78 \pm 0.11$ & $0.96 \pm 0.12$ \\
\hline & $\AA \mathrm{E}(470-660 \mathrm{~nm})$ & OPAC Derived & $1.00 \pm 0.15$ & $0.94 \pm 0.10$ & $0.75 \pm 0.10$ & $0.94 \pm 0.16$ \\
\hline & & RMSE & 0.03 & 0.02 & 0.01 & 0.02 \\
\hline & Columnar ozone (DU) & OMI & $271 \pm 10$ & $272 \pm 14$ & $261 \pm 18$ & $272 \pm 21$ \\
\hline & Precipitable water vapor $(\mathrm{cm})$ & MODIS-Terra & $2.1 \pm 0.3$ & $5.4 \pm 0.1$ & $1.9 \pm 0.3$ & $3.4 \pm 0.5$ \\
\hline \multirow{10}{*}{ 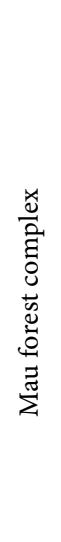 } & Rainfall (mm) & From NCEP re-analysis & 6.67 & 105.31 & 26.16 & 98.18 \\
\hline & & AERONET/MODIS & $0.16 \pm 0.03$ & $0.10 \pm 0.04$ & $0.13 \pm 0.06$ & $0.11 \pm 0.07$ \\
\hline & $\mathrm{AOD}(550 \mathrm{~nm})$ & OPAC Derived & $0.17 \pm 0.01$ & $0.12 \pm 0.07$ & $0.16 \pm 0.07$ & $0.13 \pm 0.08$ \\
\hline & & RMSE & 0.02 & 0.03 & 0.03 & 0.02 \\
\hline & & AERONET/MODIS & $1.56 \pm 0.21$ & $1.17 \pm 0.13$ & $1.57 \pm 0.10$ & $1.66 \pm 0.17$ \\
\hline & $\AA ̊ \mathrm{E}(470-660 \mathrm{~nm})$ & OPAC Derived & $1.54 \pm 0.16$ & $1.14 \pm 0.11$ & $1.56 \pm 0.17$ & $1.64 \pm 0.11$ \\
\hline & & RMSE & 0.03 & 0.03 & 0.02 & 0.03 \\
\hline & Columnar ozone (DU) & OMI & $265 \pm 10$ & $280 \pm 15$ & $261 \pm 15$ & $275 \pm 21$ \\
\hline & Precipitable water vapor $(\mathrm{cm})$ & MODIS-Terra & $1.4 \pm 0.2$ & $3.1 \pm 0.6$ & $1.1 \pm 0.8$ & $2.2 \pm 0.3$ \\
\hline & Rainfall (mm) & From NCEP re-analysis & 11.00 & 127.89 & 37.45 & 111.01 \\
\hline
\end{tabular}




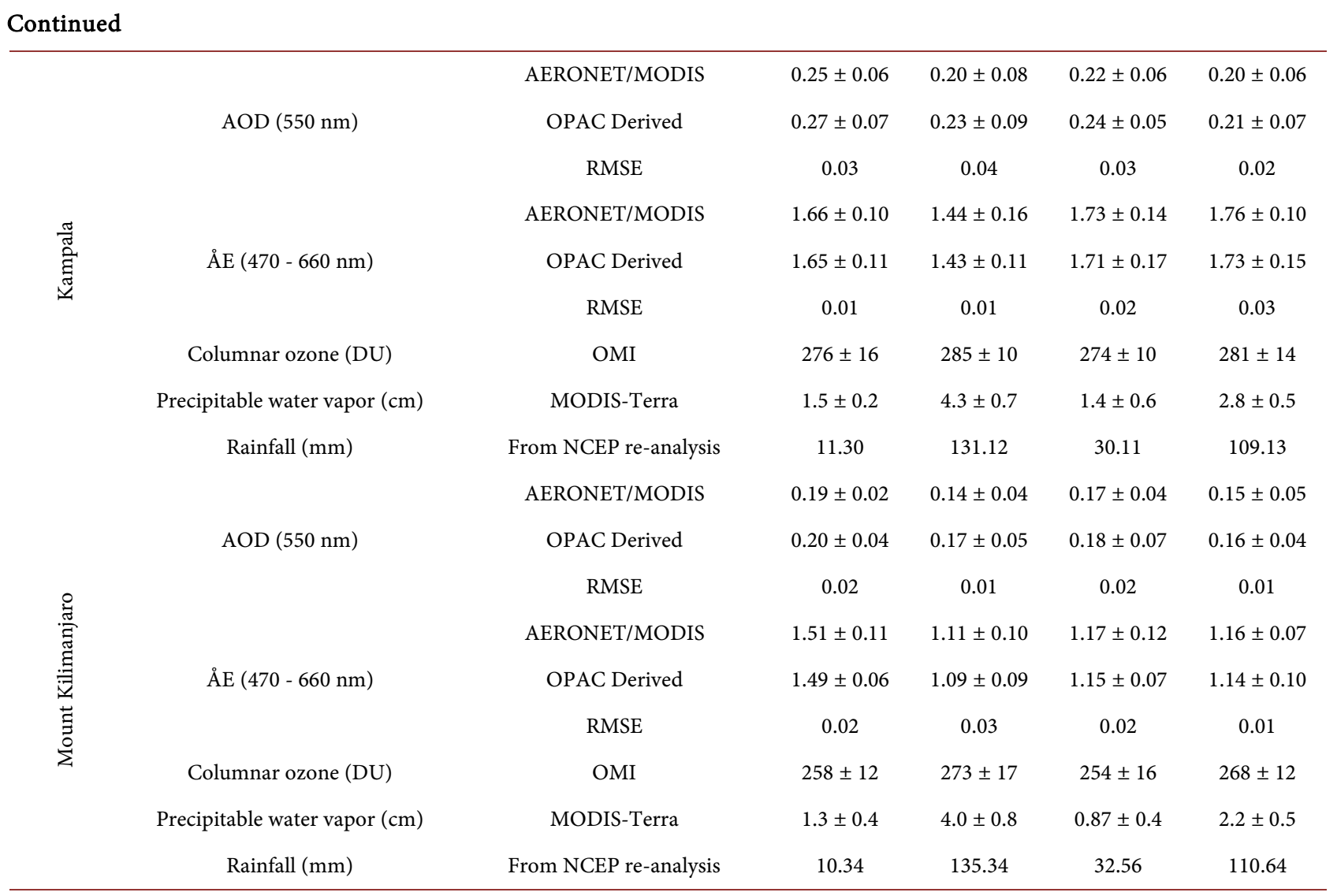

to range from 0.10 to 0.25 while the maximum uncertainties in computation of ARF were $\sim 6 \%$. Combining all these, the overall uncertainty in the estimation of daily averaged ARF combining various parameters was $\sim 19.7 \%$ falling to within the prescribed limits of between $10 \%-20 \%$ [16].

It is worth noting that both $\mathrm{ARF}_{\mathrm{TOA}}$ and $\mathrm{ARF}_{\mathrm{SFC}}$ were found to be negative with the former having a higher magnitude over each of the study sites and seasons throughout the study period. The negative ARF values indicate a cooling of the Earth-Atmosphere dominating the study sites. There was an insignificant intra-annual variability in the heating rates over each study site during the study period. Moreover, seasonal variability in the atmospheric heating rates as modulated by aerosols loading in the atmosphere was pronounced. The daily average $\mathrm{ARF}_{\text {ATM }}$ estimated over the entire East African region during the study period translates into atmospheric daily heating rates of $0.57 \mathrm{~K} /$ day, $0.54 \mathrm{~K} /$ day, 0.45 $\mathrm{K} /$ day and $0.49 \mathrm{~K} /$ day during DJF, JJA, MAM and, SON seasons, respectively for all the SZA under consideration. These heating rates are comparable to those from other regions in the tropics e.g. India where similar studies report as high as 0.42 to $0.81 \mathrm{~K} /$ day. The stated heating rates over the region imply weaker convection activities leading to less precipitation over the concerned atmosphere.

Pronounced anthropogenic activities over urban environs i.e. Nairobi and 


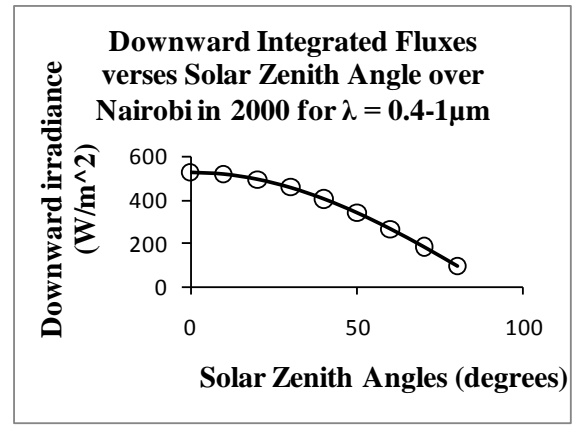

(a)

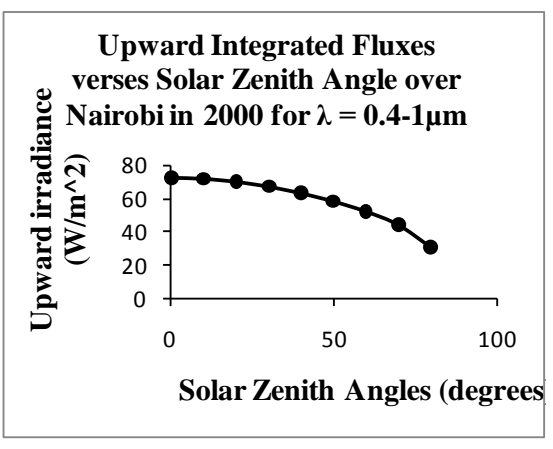

(b)

Figure 2. (a) (b) COART modeled downward and upward integrated fluxes for varying SZA respectively over Nairobi in 2000.

Kampala e.g. refuse burning, increasing populace, vehicular and industrial emissions [17]. Together with low rainfall rates that enhance dust lifting promote coarse-mode aerosols during the dry seasons (DJF and JJA). During the DJF season, the $\mathrm{ARF}_{\mathrm{SFC}}, \mathrm{ARF}_{\mathrm{TOA}}$ and $\mathrm{ARF}_{\mathrm{ATM}}$ are $-16.9 \pm 1.1 \mathrm{~W} \cdot \mathrm{m}^{-2},-1.8 \pm 0.4$ $\mathrm{W} \cdot \mathrm{m}^{-2}$ and $+15.1 \pm 0.6 \mathrm{~W} \cdot \mathrm{m}^{-2}$, respectively which translates to a daily heating rate of about $0.48 \pm 0.02 \mathrm{~K} /$ day during the study period. On the other hand, the JJA season is characterized by $\mathrm{ARF}_{\mathrm{SFC}}, \mathrm{ARF}_{\mathrm{TOA}}$ and $\mathrm{ARF}_{\mathrm{ATM}}$ of $-17.3 \pm 0.4$ $\mathrm{W} \cdot \mathrm{m}^{-2},-1.4 \pm 0.8 \mathrm{~W} \cdot \mathrm{m}^{-2}$ and $+15.9 \pm 1.9 \mathrm{~W} \cdot \mathrm{m}^{-2}$, respectively which translates to a daily heating rate of about $0.55 \mathrm{~K} /$ day for the period of study. During the wet season, Nairobi is characterized by lower $\mathrm{ARF}$ values i.e. $\mathrm{ARF}_{\mathrm{SFC}}, \mathrm{ARF}_{\mathrm{TOA}}$ and $\mathrm{ARF}_{\mathrm{ATM}}$ of about $-10.1 \pm 0.5 \mathrm{~W} \cdot \mathrm{m}^{-2},-1.7 \pm 0.3 \mathrm{~W} \cdot \mathrm{m}^{-2}$ and $+8.4 \pm 0.1 \mathrm{~W} \cdot \mathrm{m}^{-2}$, respectively (for MAM) and $-12.3 \pm 1.0 \mathrm{~W} \cdot \mathrm{m}^{-2},-1.6 \pm 1.3 \mathrm{~W} \cdot \mathrm{m}^{-2}$ and $+10.7 \pm$ $1.9 \mathrm{~W} \cdot \mathrm{m}^{-2}$, respectively (for SON). This translates to daily heating averages of $0.48 \mathrm{~K} /$ day and $0.51 \mathrm{~K} /$ day for MAM and SON seasons respectively. Increasing heating rates for both MAM and SON seasons over Nairobi necessitates strong atmospheric absorption that directly influences the regional general atmospheric circulation.

Vehicular emissions over Kampala explain the high AOD values (see Table 5.10) as compared to Nairobi throughout the study period [18]. These high AOD values explain the enhanced heating rates over the site as compared to Nairobi during the study period. During the DJF season, the $\mathrm{ARF}_{\mathrm{SFC}}, \mathrm{ARF}_{\mathrm{TOA}}$ and $\mathrm{ARF}_{\text {ATM }}$ are $-17.8 \pm 1.4 \mathrm{~W} \cdot \mathrm{m}^{-2},-1.4 \pm 0.3 \mathrm{~W} \cdot \mathrm{m}^{-2}$ and $+16.2 \pm 0.4 \mathrm{~W} \cdot \mathrm{m}^{-2}$, respectively leading to a daily heating rate of about $0.56 \pm 0.03 \mathrm{~K} /$ day during the stud period. Similarly, the JJA season is described by $A_{\mathrm{RFF}} \mathrm{SFC}_{\mathrm{ARF}} \mathrm{APA}_{\mathrm{TO}}$ and $\mathrm{ARF}_{\mathrm{ATM}}$ of $-18.1 \pm 0.2 \mathrm{~W} \cdot \mathrm{m}^{-2},-1.2 \pm 0.2 \mathrm{~W} \cdot \mathrm{m}^{-2}$ and $+16.9 \pm 1.7 \mathrm{~W} \cdot \mathrm{m}^{-2}$, respectively which translates to a daily heating rate of about $0.56 \mathrm{~K} /$ day for the period of study. The increasing heating rates during DJF and JJA seasons over Kampala imply strong atmospheric absorption that directly affects regional atmospheric dynamics.

Wet season is characterized by lower $\mathrm{ARF}$ values i.e. $\mathrm{ARF}_{\mathrm{SFC}}, \mathrm{ARF}_{\mathrm{TOA}}$ and $\mathrm{ARF}_{\mathrm{ATM}}$ of about $-12.3 \pm 0.4 \mathrm{~W} \cdot \mathrm{m}^{-2},-1.3 \pm 0.2 \mathrm{~W} \cdot \mathrm{m}^{-2}$ and $+11.0 \pm 0.6 \mathrm{~W} \cdot \mathrm{m}^{-2}$, 
respectively (for MAM) and $-13.6 \pm 1.2 \mathrm{~W} \cdot \mathrm{m}^{-2},-1.8 \pm 1.3 \mathrm{~W} \cdot \mathrm{m}^{-2}$ and $+11.8 \pm$ $1.8 \mathrm{~W} \cdot \mathrm{m}^{-2}$, respectively (For $\mathrm{SON}$ ) as compared to dry season. This translates to daily heating averages of $0.49 \mathrm{~K} /$ day and $0.52 \mathrm{~K} /$ day for MAM and SON seasons respectively. Enhanced aerosol scavenging from the atmosphere through wet deposition implies low aerosol loading which explains the decreasing heating rates observed over Kampala during wet seasons over the site.

Mbita, a rural site adjacent to Lake Victoria similarly exhibits seasonal variability in ARF but of a lower magnitude as compared to that of Nairobi as a result of declining biomass burning activities which consequently lower aerosol load in the atmosphere [8] [19] [20]. During the dry seasons i.e. DJF and JJA, the site is characterized by $\mathrm{ARF}_{\mathrm{SFC}}, \mathrm{ARF}_{\mathrm{TOA}}$ and $\mathrm{ARF}_{\mathrm{ATM}}$ of $-14.1 \pm 0.3 \mathrm{~W} \cdot \mathrm{m}^{-2},-1.4 \pm 0.7$ $\mathrm{W} \cdot \mathrm{m}^{-2}$ and $+12.7 \pm 1.4 \mathrm{~W} \cdot \mathrm{m}^{-2}$, respectively which translates to a daily heating rate of about $0.41 \mathrm{~K} /$ day for the period of study. Moreover, the wet season is characterized by $\mathrm{ARF}_{\mathrm{SFC}}, \mathrm{ARF}_{\mathrm{TOA}}$ and $\mathrm{ARF}_{\mathrm{ATM}}$ of about $-9.1 \pm 0.3 \mathrm{~W} \cdot \mathrm{m}^{-2},-1.9 \pm$ $0.1 \mathrm{~W} \cdot \mathrm{m}^{-2}$ and $+7.2 \pm 0.6 \mathrm{~W} \cdot \mathrm{m}^{-2}$, respectively (for MAM) and $-8.6 \pm 0.3 \mathrm{~W} \cdot \mathrm{m}^{-2}$, $-1.7 \pm 0.3 \mathrm{~W} \cdot \mathrm{m}^{-2}$ and $+6.9 \pm 0.6 \mathrm{~W} \cdot \mathrm{m}^{-2}$, respectively (For SON). This translates to daily heating averages of $0.41 \mathrm{~K} /$ day and $0.42 \mathrm{~K} /$ day for MAM and SON seasons respectively. The relatively constant heating rates over Mbita in all seasons are attributed to invariant aerosol loading in the atmosphere during the study period.

Maritime conditions (sea spray and sea salt) dominating Malindi plus the influence of Monsoon transportation of dust from the Arabian Peninsula [8] explains the enhanced ARF. Additionally, ARF are seasonally invariant in $\mathrm{ARF}_{\mathrm{SFC}}$, $\mathrm{ARF}_{\mathrm{TOA}}$ and $\mathrm{ARF}_{\mathrm{ATM}}$ and are estimated as $-13.4 \pm 1.8 \mathrm{~W} \cdot \mathrm{m}^{-2},+2.4 \pm 1.3 \mathrm{~W} \cdot \mathrm{m}^{-2}$ and $+16.7 \pm 2.4 \mathrm{~W} \cdot \mathrm{m}^{-2}$, respectively translating to a daily heating rate of about $0.66 \mathrm{~K} /$ day. This heating rate is the highest among all the study sites in the region. The enhanced heating rate may be attributed to high absorbing aerosol loading Monsoon transport from Arabian Peninsula dominating the site.

Mau Forest is mainly dominated by forest clearance for agricultural use and biomass burning activities [21] [22]. These activities may explain the larger AOD $(0.16 \pm 0.03$ and $0.13 \pm 0.06$ for DJF and JJA seasons respectively) as a result of inefficient dry deposition of aerosols and accelerated dust lifting from bare land due to the forest clearance. During the wet seasons i.e. MAM and SON, AOD values are slightly lower (see Table 1 ) as a result of efficient wet deposition of aerosols from the atmosphere and at the same time limiting dust lifting activities. Seasonal ARF values at the surface during DJF, MAM, JJA and SON seasons are of the order of $-16.1 \pm 1.7 \mathrm{~W} \cdot \mathrm{m}^{-2},-13.7 \pm 2.2 \mathrm{~W} \cdot \mathrm{m}^{-2},-6.5 \pm 1.3 \mathrm{~W} \cdot \mathrm{m}^{-2}$, and $-12.2 \pm 3.1 \mathrm{~W} \cdot \mathrm{m}^{-2}$, respectively during the study period. Additionally, DJF, MAM, JJA and SON seasons projected an extraterrestrial solar radiation over Mau Forest estimated around $430.68 \mathrm{~W} \cdot \mathrm{m}^{-2}, 450.30 \mathrm{~W} \cdot \mathrm{m}^{-2}, 392.79 \mathrm{~W} \cdot \mathrm{m}^{-2}$ and $437.54 \mathrm{~W} \cdot \mathrm{m}^{-2}$, respectively. Thus, the estimated ARF at the surface is -16.8 $\mathrm{W} \cdot \mathrm{m}^{-2},-14.1 \mathrm{~W} \cdot \mathrm{m}^{-2},-15.0 \mathrm{~W} \cdot \mathrm{m}^{-2}$ and $-14.8 \mathrm{~W} \cdot \mathrm{m}^{-2}$ for DJF, MAM, JJA and SON seasons respectively over Mau Forest. 
Furthermore, the stated surface ARF in each season over Mau Forest translates to a relative change in incoming solar radiation of about $3.4 \%, 3.2 \%, 5.6 \%$ and 6.4\%, in DJF, MAM, JJA and SON seasons respectively. Likewise, estimated extraterrestrial solar radiations are of magnitude of $433 \mathrm{~W} \cdot \mathrm{m}^{-2}, 448 \mathrm{~W} \cdot \mathrm{m}^{-2}, 327$ $\mathrm{W} \cdot \mathrm{m}^{-2}$ and $299 \mathrm{~W} \cdot \mathrm{m}^{-2}$ during the DJF, MAM, JJA and SON seasons respectively over Mount Kilimanjaro. This represents a relatively low percentage change incoming solar radiation of about $1.1 \%, 2.2 \%, 1.9 \%$ and $1.8 \%$, as influenced by aerosols during DJF, MAM, JJA and SON season respectively. This minimal change in the surface ARF is attributed to the concerted efforts by the relevant authorizes in mitigating deforestation activities that were prevalent over the site [23].

\section{Conclusions}

Assessment of radiative forcing due to aerosols is important in accounting for the cloud effect that has contributed to uncertainties in climate forcing estimates. This study gave radiative forcing estimates in response to optical properties of aerosols over East Africa during the period of study. Aerosol optical properties constituted the inputs of a radiative transfer model to give corresponding forcing estimates.

The study revealed that aerosols variability over the region directly increased the net atmospheric forcing which translated to an increase in the heating rate of about $0.55 \pm 0.05 \mathrm{~K} /$ day $(0.41 \pm 0.03$ to $0.78 \pm 0.03 \mathrm{~K} /$ day $)$ in the lower troposphere. This enhanced heating rate in the atmosphere has most likely contributed to increasing variability in the adiabatic lapse rate over the area of study which consequently leads to increasing variability in atmospheric stability that is characterized by varying climate over the period of study. This phenomenon can be attributed to increasing climate variability and change over the area of study.

\section{Acknowledgements}

This work was supported by the National Council for Science and Technology Grant funded by the Government of Kenya (NCST/ST \& I/RCD/4TH call $\mathrm{PhD} / 201)$. The authors wish to thank the Giovanni online data system that is developed and maintained by the NASA Goddard Earth Science Distributed Active Archive (NASA GES DISC) from which Total Ozone Column data from a number of satellites was obtained. I also acknowledge the support of the African Spectral Imaging Network (AFSIN) through funding the first author to travel to a conference on multispectral imaging in Senegal.

\section{References}

[1] Stocker, T.F., Qin, D., Plattner, G.K., Tignor, M., Allen, S.K., Boschung, J. and Midgley, B.M. (2013) IPCC 2013: Climate Change 2013: The Physical Science Basis. 5th Assessment Report of the Intergovernmental Panel on Climate Change.

[2] Makokha, J.W., Kimani, J.N. and Angeyo, H.K. (2012). Estimation of Radiative 
Forcing Due to Aerosols over Selected Sites in Kenya. Journal of Meteorology and Related Sciences, 6, 3-13.

[3] Juma, S.G., Muthama, J. and Mutai, B.K. (2015) Simulation of Radiative Forcing Due to Aerosols over Some Counties in Kenya. BEST IJHAMS, 3, 65-88.

[4] Peraiah, A. (2002) An Introduction to Radiative Transfer. Cambridge University Press, Cambridge, United Kingdom, 9-15.

[5] Grant, P.W. (2004) A First Course in Atmospheric Radiation. Madison WI USA: Sundog Publishing, 62-66.

[6] Jin, Z.H. and Stamnes, K. (1994) Radiative Transfer in Non-Uniformly Refracting Layered Media: Atmosphere-Ocean System. Applied Optics, 33, 431-442. https://doi.org/10.1364/AO.33.000431

[7] Jin, Z.H., Thomas, P., Charlock, R.K., Stamnes, K. and Wang, Y.J. (2006) Analytical Solution of Radiative Transfer in the Coupled Atmosphere-Ocean System with a Rough Surface. Optics, 45, 7443-7455.

[8] Makokha, J.W. and Angeyo, H.K. (2013) Investigation of Radiative Characteristics of the Kenyan Atmosphere Due to Aerosols Using Sun Spectrophotometry Measurements and the COART Model. Aerosol and Air Quality Research, 13, 201-208.

[9] Makokha, J.W., Odhiambo, J.O. and Godfrey, J.S. (2017) Trend Analysis of Aerosol Optical Depth and Angstrom Exponent Anomaly over East Africa. Atmospheric and Climate Sciences, 7, 588-603. https://doi.org/10.4236/acs.2017.74043

[10] Pathak, B., Kalita, G., Bhuyan, K., Bhuyan, P.K. and Moorthy, K.K. (2010) Aerosol Temporal Characteristics and Its Impact on Shortwave Radiative Forcing at a Location in the Northeast of India. Journal of Geophysical Research, 115, D19204. https://doi.org/10.1029/2009JD013462

[11] Ramachandran, S., Kedia, S. and Srivastava, R. (2012) Aerosol Optical Depth Trends over Different Regions of India. Atmospheric Environment, 49, 338-347. https://doi.org/10.1016/j.atmosenv.2011.11.017

[12] Guleria, R.P. and Kuniyal, J.C. (2015) Characteristics of Atmospheric Aerosol Particles and Their Role in Aerosol Radiative Forcing over the Northwestern India Himalaya in Particular and over India in General. Air Quality, Atmosphere \& Health, 9, 7950808.

[13] Moorthy, K.K., Nair, V.S., Babu, S.S. and Satheesh, S.K. (2009) Spatial and Vertical Heterogeneities of Aerosol Radiative Forcing over the Oceanic Regions Surrounding the Indian Peninsula: Climate Implications. Quarterly Journal of the Royal Meteorological Society, 135, 2131-2145. https://doi.org/10.1002/qj.525

[14] Liou, K.N. (2002) An Introduction to Atmospheric Radiation. $2^{\text {nd }}$ Edition, International Geophysics Series No. 84, Academic Press, Cambridge.

[15] Satheesh, S.K. and Ramanathan, V. (2000) Large Differences in the Tropical Aerosol Forcing at the Top of the Atmosphere and Earth's Surface. Nature, 405, 60-63. https://doi.org/10.1038/35011039

[16] Stone, R.S., Anderson, G.P., Andrews, E., Dutton, E.G., Shettle, E.P. and Berk, A. (2007) Incursions and Radiative Impact of Asian Dust in Northern Alaska. Geophysical Research Letters, 34, L14815. https://doi.org/10.1029/2007GL029878

[17] van Vliet, E.D.S. and Kinney, P.L. (2007) Impacts of Roadway Emissions on Urban Particulate Matter Concentrations in Sub-Saharan Africa: New Evidence from Nairobi, Kenya. Environmental Research Letters, 2, 045028. https://doi.org/10.1088/1748-9326/2/4/045028

[18] Mabasi, T. (2009) Assessing the Impacts, Vulnerability, Mitigation, and Adaptation 
to Climate Change in Kampala City. 5th Urban Research Symposium 2009, Kampala, Uganda.

[19] Ngaina, J.K. and Mutai, B.K. (2013) Observational Evidence of Climate Change on Extreme Events over East Africa. Global Meteorology, 2, 6-12.

https://doi.org/10.4081/gm.2013.e2

[20] Ngaina, J.N., Mutai, B.K., Ininda, J.M. and Muthama, J.N. (2014) Monitoring Spatial-Temporal Variability of Aerosol over Kenya. Ethiopian Journal of Environmental Studies and Management, 7, 244-252. https://doi.org/10.4314/ejesm.v7i3.3

[21] National Environmental Management Authority, Kenya (NEMA) (2013) Mau at a glance. NEMA Report.

[22] Mutugi, M. and Kiiru, W. (2015) Biodiversity, Local Resource, National Heritage, Regional Concern and Global Impact: The Case of Mau Forest, Kenya. ESJ, 1, 681-691.

[23] Fairman, J.G., Nair, U.S., Christopher, S.A. and Mölg, T. (2011) Land Use Change Impacts on Regional Climate over Kilimanjaro. Journal of Geophysical Research Atmospheres, 116, D03110. https://doi.org/10.1029/2010JD014712 